\title{
МЕТОДЫ ПРЕДИКТИВНОЙ АНАЛИТИКИ ЭФФЕКТИВНОСТИ РАБОТЫ ОБОРУДОВАНИЯ МАШИНОСТРОИТЕЛЬНОГО ПРЕДПРИЯТИЯ
}

\author{
(c) 2020 Мильская Елена Андреевна \\ доктор экономических наук, профессор \\ Институт промышленного менеджмента, экономики и торговли \\ Санкт-Петербургский политехнический университет Петра Великого (СПбПУ), \\ Россия, Санкт-Петербург \\ Email: santa-2000@mail.ru \\ (C) 2020 Забелин Борис Федорович \\ кандидат экономических наук \\ Институт промышленного менеджмента, экономики и торговли \\ Санкт-Петербургский политехнический университет Петра Великого (СПбПУ), \\ Россия, Санкт-Петербург \\ Email: zabelinbf@mail.ru

\section{(c) 2020 Никишин Вадим Михайлович} \\ кандидат экономических наук, доцент \\ Санкт-Петербургский государственный электротехнический университет «ЛЭТИ» \\ им. В. И. Ульянова (Ленина), Россия, Санкт-Петербург \\ (c) 2020 Мошнов Александр Николаевич \\ кандидат экономических наук, доцент \\ Санкт-Петербургский государственный электротехнический университет «ЛЭТИ» \\ им. В. И. Ульянова (Ленина), Россия, Санкт-Петербург \\ Email:amoshov@mail \\ (c) 2020 Пономарева Ольга Алексеевна \\ кандидат экономических наук, доцент \\ Институт промышленного менеджмента, экономики и торговли \\ Санкт-Петербургский политехнический университет Петра Великого (СПбПУ), \\ Россия, Санкт-Петербург \\ Email: ponomareva@kafedrapik.ru
}

Можно говорить, что в наш мир ворвался модный тренд в аналитике - предиктивная аналитика. Статья посвящена анализу методов, задач и результатов предиктивной аналитики эффективности работы оборудования промышленного предприятия.

Ключевые слова: предиктивная аналитика на производстве, аналитика эффективности работы оборудования, КРІ показатели.

\section{1. Введение}

В настоящее время, а именно об этом нам сегодня хотелось бы поговорить, появилось модное направление в аналитике - predictive analytics. Какие же вопросы решает на производстве предиктивная аналитика. Хотелось бы осветить в данной статье прогнозирование технического состояния оборудования. При этом решаются следующие задачи [1-5]:

- предотвращаются остановки в работе оборудования путем перехода на ремонт оборудо- вания по состоянию;

- оценивается техническое состояние оборудования в реальном времени;

- выявляются причины поломки оборудования;

- происходит получение оповещений о приближающихся сбоях и отказах.

OEE (Overall Equipment Effectiveness) - подход к наблюдению и управлению жизненным циклом производственных фондов.

Суть подхода заключается в совокупном 
анализе метрик, характеризующих различные аспекты работы оборудования, включающие простои, снижение скорости и потери качества [4].

В его структуре уже содержится методика анализа, которая заключается в последовательном погружении в проблемные области, будь то неоптимальная организация работы оборудования, низкая его производительность или брак получаемой продукции [5,6]. В результате анализа выявляется причина снижения эффективности, на которой необходимо сфокусировать внимание.

OEЕ позволяет выявить потери и причины неэффективности работы. В результате выявляются не только простои из-за поломок, но и потери из-за неэффективной настройки оборудования, снижения производительности его работы или ожидания поступления материалов. В конечном итоге ОЕЕ позволяет проследить, каково влияние текущей производительности отдельной единицы оборудования на эффективность работы целого производства [7].

Наличие достоверных результатов измерения производительности фондов позволяет принимать взвешенные решения о капитальных вложениях, обеспечивающих более быстрый возврат инвестиций [8]. На основе данных ОЕЕ делается вывод, возможно ли улучшение производительности на существующем оборудовании или же его возможности фактически исчерпаны и для увеличения производительности необходимо новое.

Цель данной статьи: на основе анализа публикаций выбрать показатели для предиктивой аналитики эффективности работы оборудования машиностроительного предприятия.

\section{2. Методы}

Для анализа эффективности работы оборудования разработана система КPI (Key Performance Indicators - ключевых показателей производительности). Но перед тем как начать их рассматривать, необходимо договориться о терминологии. Как уже было сказано, ОЕЕ - это подход к наблюдению за работой оборудования [9-12].

С учетом потерь производительности и качества этот коэффициент может быть рассчитан по формуле 1.

OEE $=$ Доступность $\times$ Производительность $\times$

Качество,

где:

Доступность = Рабочее время / Плановое время;

Производительность = Произведенная продукция /(Идеальная скорость × Рабочее время);

Качество = Качественная продукция / Произведенная продукция.

Разумеется, набор КРІ для оценки эффективности работы не ограничивается описанными четырьмя показателями $[11,12]$. Они являются наиболее общими и в дальнейшем детализируются до необходимого уровня. Другие важные показатели будут рассмотрены нами ниже.

Одной из главных целей ОЕЕ является снижение шести наиболее значительных причин потери эффективности (Six Big Losses), перечисленных в таблице 1 [12].

\section{3. Результаты}

Автоматизированная система контроля станочного парка машиностроительного предприятия производит расчет и архивирование следующих данных:

- коэффициент запланированного времени Кзв;

Таблиц̧а 1. Six Big Losses

\begin{tabular}{|l|l|l|}
\hline \multicolumn{1}{|c|}{ Причина } & \multicolumn{1}{|c|}{ Категория } & \multicolumn{1}{|c|}{ Примечание } \\
\hline Поломка & Потери из-за простоев & $\begin{array}{l}\text { Существует определенная свобода в том, что } \\
\text { относить к поломкам, а что к мини-остановкам }\end{array}$ \\
\hline Настройка & Потери из-за простоев & Включает смену и перенастройку инструментов \\
\hline Мини-остановка & Потеря скорости & $\begin{array}{l}\text { Обычно включает остановки на время меньшее, } \\
\text { например, пяти минут }\end{array}$ \\
\hline Снижение скорости & Потеря скорости & $\begin{array}{l}\text { Все, что не позволяет процессу работать на максимально } \\
\text { возможной скорости }\end{array}$ \\
\hline Брак при запуске & Потеря качества & $\begin{array}{l}\text { Брак, возникающий при прогреве, запуске и на прочих } \\
\text { ранних стадиях производства }\end{array}$ \\
\hline Брак при производстве & Потеря качества & Брак, возникающий при обычной работе производства \\
\hline
\end{tabular}


- коэффициент доступного времени Кдв;

- коэффициент полезного времени Кпв;

- коэффициент качественных незапланированных операций Ккно;

- коэффициент некачественных незапланированных операций Кнно;

- общая эффективность оборудования на основе ввода данных оператора OEE;

- абсолютная эффективная производительность оборудования на основе ввода данных оператора TEEPo;

- абсолютная эффективная производительность оборудования на основе автоматического контроля ТЕЕРа.

1. Кзв - коэффициент запланированного времени.

$$
\text { Кзв = Зв / Кв, }
$$

где:

Кв - календарное время;

Зв - запланированное время.

Кв за день = 24 часа; Кв за неделю $=7$ дней; Кв за месяц $=28 \div 31$ день; Кв за квартал = 3 месяца; Кв за год = 4 квартала.

Зв $=$ Кв - Незапланированное время

K незапланированному времени относятся следующие статус-периоды станка:

- праздничные дни;

- выходные дни;

- пересменки;

- официальные совещания;

- обеды;

- официально выделенное время на осмотр, обслуживание и ППР станка;

- официально выделенное время на отработку новой технологии;

- официально выделенное время на отработку новой программы;

- прочие официальные регламентируемые мероприятия;

- нерабочее время.

2. Кдв - коэффициент доступного времени.

$$
\text { Кдв = Дв } / \text { Зв, }
$$

где:

Зв - запланированное время;

Дв - доступное время.

$$
\text { Дв }=\text { Зв - Потери доступности }
$$

K потерям доступности относятся следую- щие статус-периоды станка:

- незапланированный невыход оператора (болезнь, прогул и т.п.);

- поломка и ремонт оборудования;

- отсутствие задания;

- отсутствие материала;

- отсутствие инструмента;

- отсутствие крана;

- отсутствие вспомогательного оборудования.

3. Кпв - коэффициент полезного времени.

$$
\text { Кпв }=\text { Пв / Дв, }
$$

где:

Дв - доступное время;

Пв - полезное время.

Пв = Дв - Потери неосновных операций (7)

К потерям неосновных операций относятся следующие статус-периоды станка:

- раскладка инструмента в начале смены;

- уборка инструмента и места в конце смены;

- получение и установка инструмента, приспособлений;

- снятие/сдача инструмента и приспособлений;

- установка и снятие детали со станка;

- переналадка станка на новую деталь;

- предусмотренный техпроцессом контроль детали на станке;

- личные надобности.

4. Ккно - коэффициент качественных незапланированных операций.

$$
\text { Ккно }=\text { Св } / \text { Пв, }
$$

где:

Пв - полезное время;

Св - стандартное время.

Св $=$ Пв - Качественные незапланированные операции

K качественным незапланированным операциям относятся следующие статус-периоды станка:

- замена/заточка изношенного инструмента;

- подналадка оборудования в процессе операции;

- управление оборудованием (изменение режимов его работы).

5. Кнно - коэффициент некачественных 
незапланированных операций.

$$
\text { Кнно }=\text { ЧВо } / \text { Св, }
$$

где:

Св - стандартное время;

ЧВо - чистое время на основе ввода данных оператора.

ЧВо $=$ Св - Собственные некачественные незапланированные операции - Чужие некачественные незапланированные операции

K собственным некачественным незапланированным операциям относятся следующие статус-периоды станка:

- исправление брака данного станка.

K чужим некачественным незапланированным операциям относятся следующие статуспериоды станка:

- исправление брака другого станка.

6. ОЕЕ - общая эффективность оборудования на основе ввода данных оператора.

$$
\text { ОЕЕ = Кдв * Кпв * Ккно * Кнно, }
$$

где:

Кдв - коэффициент доступного времени;

Кпв - коэффициент полезного времени;

Ккно - коэффициент качественных незапланированных операций;

Кнно - коэффициент некачественных незапланированных операций;

7. TEEРо - абсолютная эффективная производительность оборудования на основе ввода данных оператора.

$$
\text { TEЕРо = Кзв * Кдв * Кпв * Ккно * Кнно, }
$$

где:

Кзв - коэффициент запланированного времени;

Кдв - коэффициент доступного времени;

Кпв - коэффициент полезного времени;

Ккно - коэффициент качественных незапланированных операций;

Кнно - коэффициент некачественных незапланированных операций;

или

$$
\mathrm{TEEPo}=\text { ЧВo } / \mathrm{KB}
$$

где:

Кв - календарное время;

ЧВо - чистое время на основе ввода данных оператора.

8. ТЕЕРа - абсолютная эффективная производительность оборудования на основе автоматического контроля.

$$
\mathrm{TEEPa}=\text { Чв } / \text { Кв, }
$$

где:

Кв - календарное время;

Чв - чистое время на основе автоматического контроля.

\section{4. Предложения}

Предложенная автоматизированная система контроля станочного парка машиностроительного предприятия позволяет в автоматическом режиме рассчитывать показатели OEE, TEEPo, TEEPa.

Использование методов предиктивной аналитики для анализа показателей эффективности оборудования позволит повысить эффективную производительность оборудования.

\section{5. Заключение}

Предиктивная аналитика, основанная на применении современных программных продуктов, эффективно решает задачи и дает прекрасные результаты. Проведя анализ методов предиктивной аналитики предложены ключевые показатели эффективности (KРI).

Для дальнейшего использования результатов статьи необходимо:

1. Внедрить на предприятиях машиностроения систему ручного ввода данных оператором для расчета показателей TЕEРо.

2. Оснастить системой датчиков конкретное оборудование предприятия.

Использование системы датчиков позволит снимать данные в автоматическом режиме для расчета абсолютной эффективной производительности оборудования (ТЕЕРа).

Анализ (сравнение) этих двух показателей даст возможность:

- сократить время простоя оборудования;

- снизить затраты на ремонт оборудования;

- уменьшить количество неплановых ремонтов;

- осуществлять контроль нарушений;

- повысить эффективность в управлении предприятием машиностроения. 


\section{Библиографический список}

1. Shchepinin V.E., Leventsov V.A., Zabelin B.F., Konnikov E. A., Kasianenko E. O. The Content Aspect of the Tendency to Reflect the Actual Result of Management. Reliability, Infocom Technologies and Optimization (Trends and Tuture Directions) 6th International Conference ICRITO. 2017. C. 657-662.

2. Цырков А.В., Цырков Г. А., «Интеллектуальные компоненты для поддержки рабочих процессов в проектной и производственной деятельности». Международная конференция «Управление качеством, транспорт и информационная безопасность, информационные технологии» (IT \& QM \& IS), Санкт-Петербург, 2017 г., стр. 780-784. doi: 10.1109 / ITMQIS.2017.8085942

2. Исламова О.В., Жиляев А.А., Бозиева А. М. «Технология SADT как инструмент повышения эффективности использования процессного подхода в управлении машиностроительным предприятием», конференция IEEE 2016 года по управлению качеством, транспорту и информационной безопасности, информационным технологиям (IT \& MQ \& IS), Нальчик, 2016, с. 65-68. doi: 10.1109 / ITMQIS.2016.7751903

3. Zabelin B., Romashkin G., Antipov D. Predictive Analytics as a Tool for a Powerful Leap of the Modern Economy. Proceedings of the 33rd International Business Information Management Association Conferece, IBIMA 2019: Edication Excellence and Innovation Management through Vision 20202019. C. 8774-8782.

4. А.М.Дворянкин, В.А. Камаев, А.В. Кизим, «Интеллектуальная автоматическая система поддержки главного конструктора машиностроительной продукции», Труды 2002 IEEE Международная конференция по системам искусственного интеллекта (ICAIS 2002), 2002, с. 177-179. doi: 10.1109 / ICAIS.2002.1048083

5. Г. Г. Куликов, А.В.Речкалов, Л. Р. Черняховская и А. Н. Набатов. Метод моделирования информационных систем управления производством (для машиностроительного завода). Симуляция. Международная конференция (Conf. Publ. № 457), York, 1998, pp. 240-243. doi: 10.1049 / сp: 19980644

6. Исламова О.В., Жиляев А. А. «Реализация принципов управления рисками в модели бизнес-процессов машиностроительного предприятия». Международная конференция «Управление качеством, транспорт и информационная безопасность, информационные технологии» (IT \& QM \& IS), Санкт-Петербург, 2017, с. 528-530. doi: 10.1109 / ITMQIS.2017.8085877

7. А.В. Лопота, А.В.Цырков, Г.А.Цырков, «Методы и инструменты проектно-эксплуатационного управления машиностроительным предприятием», Международная конференция 2017 года «Управление качеством, транспорт и информационная безопасность, информационные технологии» (IT \& QM \& IS), СанктПетербург, 2017, с. 544-547. doi: 10.1109 / ITMQIS.2017.8085882

8. С.В. Краснов, С. М. Сергеев, Н.В. Муханова и А.Н.Грушкин, «Методическое формирование деловых компетенций для частного бренда», 2017 г. 6-я Международная конференция по надежности, инфокоммуникационным технологиям и оптимизации (тенденции и направления будущего) (ICRITO), Нойда, Индия, 2017 г., стр. 553-558. doi: 10.1109 / ICRITO.2017.8342489

9. Родионов Д.Г., Рудская И. А., Дегтерева В. А., Оценка эффективности региональных инновационных систем в России. Материалы 29-й конференции Международной ассоциации по управлению деловой информацией - «Превосходство в образовании и управление инновациями через видение 2020: от устойчивости регионального развития к глобальному экономическому росту», 2017, с. 3437-3450.

10. Ниязова С.Р., Купоров Ю.Ю., Надежина О.С. Разработка модели адаптивного управления инновационной деятельностью предприятия. Материалы 28-й Международной конференции Ассоциации управления деловой информацией - Vision 2020: управление инновациями, устойчивость развития и конкурентный экономический рост, 2016, с. 2210-2222. 